\title{
Two ways, one goal: To improve quality of life of people with Diabtes and their family
}

\author{
Manuel Vera Gonzalez ${ }^{1 *}$ and Rocio Rodriguez Sanchez ${ }^{2}$ \\ ${ }^{1}$ Department of Endocrinology, Cuba \\ ${ }^{2}$ Department of Endocrinology, Cuba
}

ISSN: 2576-9200

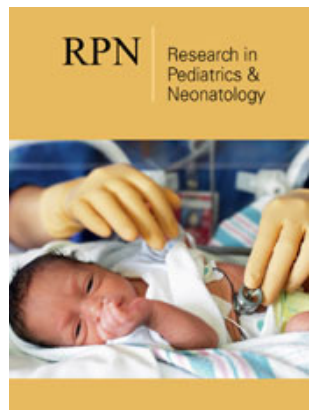

${ }^{* 1}$ Corresponding author: Manuel Vera Gonzalez, Consultant Professor National Institute of Endocrinology, Cuba

Submission: 監August 13, 2019

Published: 侮 August 19, 2019

Volume 3 - Issue 3

How to cite this article: Manuel $\mathrm{V}$ G Rocio R S. Two ways, one goal: To improve quality of life of people with Diabtes and their family. 3(3).RPN.000568.2019. DOI: $10.31031 /$ RPN.2019.03.000569

Copyright@ Manuel Vera Gonzalez, This article is distributed under the terms of the Creative Commons Attribution 4.0 International License, which permits unrestricted use and redistribution provided that the original author and source are credited.

\section{Opinion}

Therapeutic education for children and adolescents with diabetes should begin the moment of onset and never ends, it also must include the family (parents, grandparents, sisters and brothers, among all) Education for people with diabetes must be a continuous process that involves not only people with diabetes, but also their family, friends, couples and anyone that is part of the patient's environment Children and adolescents has certain particularities that must be taken into account by the health care team at the moment of choosing an education technique that should be pleasant, nice and raise interest of educands. We have the experience of two programs of therapeutic education for children and adolescents with diabetes and their family.

\section{General objective}

To stimulate healthy lifestyle in people with DM and their family in the community.

\section{Specific objectives}

A. Achieve acceptance of the condition of beina person with Diabetes

B. Increase Diabetes education

C. Evaluate and increase metabolic control

D. Evaluate and improve (if necessary) self-steam

E. Evaluate and improve (if necessary) quality of life

F. Prevent diabetes complication

\section{Methodological design}

The research design is a practice action. With a mixed methodological perspective. We will make questionnaires related with the referred topics to our patients. According to the response we will focus our action individually.

\section{Convivencias}

Vacational camps for children and adolescents with diabetes were first established in Cuba in 1969. In the decade of the 90's, due to a severe economic crisis, the activity was suspended in the capital and in most of the provinces within the country. At the middle of 1993, and as alternative means to summer camps, Convivencia's began. An outpatient educational clinic in which both patients and their families actively participate. Patients are admitted in a one week of day admission (daytime clinic), during which a complete clinical checkup, laboratory exams, ophthalmological, feet and dental checkup to children and adolescents with diabetes is done. We offered update information on diabetes. Topics are the same for both groups pointing out the preferences for patients and parents. Insulin shots as well as glycemic monitoring is done every day.

Educational program is made according to the Cuban educational program for diabetes adapted to pediatric ages by the educator and discussed by all the health care team. We have 
two periods per year, one for patients under 12 years old and the other from 13 to 19 years old. According with the age group classes are given, (hypos, and hyperglycemias, sexual protection, healthy eating, pregnancy and DM, among others) This year Convivencias has arrived at 26 years old. Up to now we have seen almost 1,000 patients and their family. Patients an parents catalogue Convivencia's as instructive, successful and fun, they find a backup net that is for the rest of their life and children and adolescents learn how to live with diabetes and be happy.

In order to give continuity to this program, we create the project 2 "sweet my life, not my body" in 2010. This program is a systematic educational program for patients, parents, friends, and couples among others. Is directed by young people with diabetes under the supervision and orientation of Dr. Manuel Vera. The topics are prepared, discussed and presented by the young people with diabetes members, and always supervised by medical doctor experts in each topic. We meet every Saturday of the month and have workshops with different topics related with diabetes. Workshops are selected, prepared and presented by the volunteer member; health care team is in charge to give clarification to any doubts. At this moment, we have 200 participants (patients, parents and couples, among others). We created our logo.

Universe sample: All the people who live with diabetes, relatives and friends who are part of the group Sweet my life, not the body.

Inclusion criteria: People living with diabetes mellitus, friends and relatives, regardless of their age, sex or other distinction.

Our vision: All members of our group will make its effort in achieving good metabolic control and represent an example for people with diabetes and in the community. 